\title{
Role of Hypermethylation of DAP-Kinase CpG Island in the Development of Thyroid Lymphoma
}

\author{
Shin-ichi Nakatsuka, Tetsuya Takakuwa, Yasuhiko Tomita, Hideaki Miwa, \\ Fumio Matsuzuka, and Katsuyuki Aozasa
}

Department of Pathology (SN, TT, YT, HM, KA), Osaka University Graduate School of Medicine, Osaka, and Section of Surgery (FM), Kuma Hospital, Kobe, Japan

\begin{abstract}
SUMMARY: Death-associated protein-kinase (DAP-Kinase) is a serine/threonine kinase with a death domain that is involved in apoptosis induced by interferon- $\gamma$, TNF- $\alpha$, and Fas ligand. Epigenetic down-regulation of DAP-Kinase gene expression by hypermethylation of its promoter region was reported in B-cell malignancies. Previous pathoepidemiologic studies indicated that thyroid lymphoma (TL) evolves among active lymphoid cells in chronic lymphocytic thyroiditis (CLTH). With use of methylationspecific polymerase chain reaction, the methylation status of DAP-Kinase $\mathrm{CpG}$ island was examined in thyroid lesions of 19 cases with TL and 9 with CLTH. The frequency of methylation was higher in TL cases (16 of 19,84.2\%) than in CLTH cases (2 of 9 , $22.2 \%)(p<0.01)$. DNA extracted from peripheral blood leukocytes from TL and CLTH cases never showed methylation, indicating that the methylation occurred somatically in the lesional lymphocytes in thyroid. These findings suggested that methylation of the DAP-Kinase promoter region might be involved in the development of TL from CLTH. (Lab Invest 2000, 80: 1651-1655).
\end{abstract}

$T$ he death-associated protein-kinase (DAP1 Kinase) gene is one of the genes isolated as a positive mediator of interferon- $\gamma(\mathrm{IFN}-\gamma)$-induced apoptosis by the functional approach of gene cloning based on transfections of HeLa cells with antisense cDNA libraries (Deiss and Kimchi, 1991). DAP-Kinase is a $160-\mathrm{kD}$ calcium/calmodulin-dependent serine/ threonine kinase with a death domain (Deiss et al, 1995). Overexpression of DAP-Kinase induces the death of HeLa cells without external stimuli, whereas the catalytically inactive mutant of this gene prevents cells from IFN- $\gamma$-induced apoptosis in a dominant negative manner (Cohen et al, 1997). Recent studies demonstrated that DAP-Kinase also participates in TNF- $\alpha$ - and Fas-induced apoptosis (Cohen et al, 1999). Loss of DAP-Kinase expression enhances metastatic activity of lung carcinoma cells in the experimental model (Inbal et al, 1997).

Cell lines of various carcinomas and B-cell lymphomas are resistant to IFN- $\gamma$-induced apoptosis through decrease or absence of expression of DAP-Kinase at mRNA or protein levels (Katzenellenbogen et al, 1999; Kissil et al, 1997). IFN- $\gamma$-induced apoptosis could be restored in some of these cell lines through enhanced

Received June 6, 2000.

Supported in part by grants from the Ministry of Education, Science and Culture (10042005, 10151225, 11470353, 11670212, 11680546, 12576004), Japan.

Address reprint requests to: Dr. Katsuyuki Aozasa, Department of Pathology (C3), Osaka University Graduate School of Medicine, 2-2 Yamadaoka, Suita, Osaka 565-0871, Japan. Fax: 8166879 3713; E-mail: aozasa@molpath.med.osaka-u.ac.jp expression of DAP-Kinase by treatment with 5-aza-2'deoxycytidine, a DNA demethylating agent (Kissil et al, 1997), indicating that decrease or absence of expression of DAP-Kinase was induced by methylation of the DAPKinase gene. Methylation was reported to occur also in primary tumor samples, such as B-cell malignancies (Katzenellenbogen et al, 1999). These findings suggest that hypermethylation of DAP-Kinase promoter region epigenetically reduces gene expression, thus cells are rescued from apoptosis. Such an epigenetic downregulation of gene expression through methylation of the promoter region is important as an alternative to loss of gene function by deletion or mutation (Counts and Goodman, 1995; Laird and Jaenisch, 1996).

Thyroid lymphoma (TL) is a minor constituent of non-Hodgkin's lymphomas (NHL) of B-cell type (Aozasa et al, 1987). Epidemiologic studies revealed that the frequency of $T L$ in patients with chronic lymphocytic thyroiditis (CLTH), an organ-specific autoimmune disease, is 67 to 80 times higher than that in age- and sex-matched normal individuals (Aozasa, 1990; Holm et al, 1985). Among TL patients serum antibodies against thyroglobulin and/or microsomes were positive in $80 \%$ of cases, and histologic examination of thyroid lesions revealed the presence of CLTH in almost all TL cases (Aozasa, 1990). These findings indicated that TL evolves among active lymphoid cells in CLTH. In this study we investigated the methylation status of DAP-Kinase promoter region in TL and CLTH cases to examine whether the hypermethylation of this gene is involved in the development of TL from CLTH. 


\section{Results}

\section{Histologic Findings}

TL cases comprised 9 diffuse large B-cell lymphomas, 5 follicle center cell lymphomas, and 5 marginal zone B-cell lymphomas (Table 1). Immunohistochemistry revealed that all $\mathrm{TL}$ cases showed $\mathrm{B}$-cell phenotypes, namely, $\mathrm{CD}^{+} \mathrm{O}^{+}$and/or $\mathrm{MB}-1^{+}, \mathrm{CD}^{-}{ }^{-}, \mathrm{CD}_{4} \mathrm{RO} \mathrm{O}^{-}$.

\section{Methylation-Specific PCR for the DAP-Kinase Promoter Region}

To confirm the efficacy of the procedure, methylationspecific PCR (MSP) was performed on two control cell lines with proven methylation status of DAP-Kinase gene. Raji showed amplification in the reaction for methylated sequences, but not for unmethylated sequences; whereas a lymphoblastoid cell line showed amplification only for the unmethylated sequences (Fig. 1).

The results of MSP in TL and CLTH cases are summarized in Tables 1 and 2, and representative cases are illustrated in Figure 1. The frequency of cases with hypermethylation of DAP-Kinase promoter region in TL (16 of 19 cases; $84.2 \%$ ) was significantly higher than that in CLTH (2 of 9 cases; $22.2 \%)(p<$ $0.01)$. In the TL cases, each case of diffuse large B-cell lymphoma, follicle center cell lymphoma, and marginal zone B-cell lymphoma showed no hypermethylation. In the CLTH cases, duration in two cases with hypermethylation was 6 and 40 years and in seven cases without hypermethylation ranged from 1 to 28 (median 6 ) years. Age at surgery or biopsy in cases with and without hypermethylation was 52 and 68 years and ranged from 50 to 67 (median 61) years, respectively. Histologically 1 of 2 CLTH cases with hypermethylation showed a severe lymphocytic infiltration. Even so, two CLTH cases with hypermethylation showed no clonal rearrangement of immunoglobulin heavy chain gene by Southern blot analysis (Table 1), confirming the reactive nature of thyroid lesions in these cases.

In 14 cases in which the DAP-Kinase promoter region in the thyroid lesion sample proved to be

Table 1. Methylation Status of DAP-Kinase Promoter Region in Cases with Thyroid Lymphoma and Chronic Lymphocytic Thyroiditis

\begin{tabular}{|c|c|c|c|c|c|c|}
\hline \multirow[b]{2}{*}{ No. } & \multirow[b]{2}{*}{ Sex } & \multirow[b]{2}{*}{ Age } & \multirow[b]{2}{*}{ Histology } & \multirow{2}{*}{$\begin{array}{l}\mathrm{IgH} \text { chain } \\
\text { rearrangement }\end{array}$} & \multicolumn{2}{|c|}{ Methylation } \\
\hline & & & & & Thyroid & PBL \\
\hline \multicolumn{7}{|c|}{ Thyroid lymphoma } \\
\hline 1 & $\mathrm{~F}$ & 27 & DLB & $\mathrm{R}$ & - & nd \\
\hline 2 & $\mathrm{~F}$ & 45 & DLB & $\mathrm{R}$ & + & - \\
\hline 3 & $\mathrm{~F}$ & 60 & DLB & $\mathrm{R}$ & + & nd \\
\hline 4 & $\mathrm{~F}$ & 61 & DLB & $R$ & + & - \\
\hline 5 & M & 67 & DLB & $\mathrm{R}$ & + & - \\
\hline 6 & $\mathrm{~F}$ & 71 & DLB & G & + & nd \\
\hline 7 & $\mathrm{~F}$ & 80 & DLB & $\mathrm{R}$ & + & - \\
\hline 8 & M & 81 & DLB & nd & + & - \\
\hline 9 & $\mathrm{~F}$ & 89 & DLB & $\mathrm{R}$ & + & nd \\
\hline 10 & $F$ & 48 & FCCL & $\mathrm{R}$ & + & - \\
\hline 11 & $\mathrm{~F}$ & 50 & FCCL & $\mathrm{R}$ & + & - \\
\hline 12 & $\mathrm{~F}$ & 54 & FCCL & $R$ & + & - \\
\hline 13 & $\mathrm{~F}$ & 60 & FCCL & $\mathrm{R}$ & - & nd \\
\hline 14 & $\mathrm{~F}$ & 70 & FCCL & $R$ & + & - \\
\hline 15 & M & 65 & MZL & nd & + & - \\
\hline 16 & $\mathrm{~F}$ & 70 & MZL & nd & + & nd \\
\hline 17 & $\mathrm{~F}$ & 72 & MZL & $R$ & + & - \\
\hline 18 & $\mathrm{~F}$ & 73 & MZL & G & + & - \\
\hline 19 & $\mathrm{~F}$ & 73 & MZL & $\mathrm{R}$ & - & nd \\
\hline \multicolumn{7}{|c|}{ Chronic lymphocytic thyroiditis } \\
\hline 20 & $\mathrm{~F}$ & 50 & & G & - & nd \\
\hline 21 & $\mathrm{~F}$ & 52 & & G & + & - \\
\hline 22 & $\mathrm{~F}$ & 55 & & nd & - & nd \\
\hline 23 & $\mathrm{~F}$ & 57 & & $\mathrm{G}$ & - & nd \\
\hline 24 & $\mathrm{~F}$ & 61 & & nd & - & nd \\
\hline 25 & $\mathrm{~F}$ & 66 & & nd & - & nd \\
\hline 26 & $\mathrm{~F}$ & 66 & & nd & - & nd \\
\hline 27 & $\mathrm{~F}$ & 67 & & nd & - & nd \\
\hline 28 & $\mathrm{~F}$ & 68 & & $\mathrm{G}$ & + & - \\
\hline
\end{tabular}

DLB, diffuse large B-cell lymphoma; FCCL, follicle center cell lymphoma; MZL, marginal zone B-cell lymphoma; PBL, peripheral blood leukocytes; G, germline; R, rearranged; nd, not done. 
methylated, methylation status of DNA in the peripheral blood leukocytes (PBL) was also examined to evaluate whether methylation occurred at germline gene. None of the cases showed methylation in PBL samples (Fig. 1), indicating the absence of methylation at germline gene.

\section{Discussion}

In this study hypermethylation of the DAP-Kinase promoter region was observed in 16 of 19 cases (84.2\%) with TL (Table 1, Fig. 1). A previous report showed the similar results that $84 \%$ of B-cell lymphomas (although their histologic types and site of origin were not described) had methylated promoter regions of DAP-Kinase gene (Katzenellenbogen et al, 1999), whereas hypermethylation was observed in fewer cases with CLTH (2 of 9 cases, $22.2 \%$ ) than those with TL ( $p<0.01$; Table 2). No significant differences in histologic findings were observed between TL cases with and without hypermethylation. One of two CLTH cases with hypermethylation histologically showed severe lymphocytic infiltration in the thyroid gland, but clonal rearrangement of immunoglobulin heavy chain gene was not found even in this case. Duration of CLTH seemed to be longer in CLTH cases with hypermethylation than those without, although definitive conclusions could not be drawn because of the small number of cases with hypermethylation.

In 14 cases with methylated DAP-Kinase promoter region in the thyroid lesions, methylation status in the PBL was also examined. The results showed absence

A
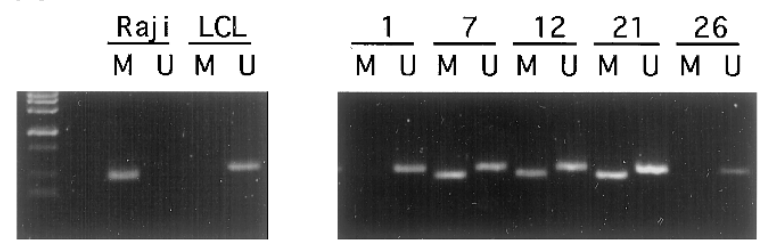

B

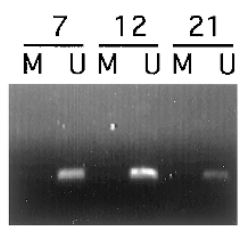

Figure 1.

Results of methylation-specific PCR (MSP) for methylation status of the DAP-Kinase promoter region. $M$ and $U$ indicate reactions using primers specific for methylated and unmethylated sequences, respectively. The size of MSP products for the methylated and the unmethylated reaction is $98 \mathrm{bp}$ and $106 \mathrm{bp}$, respectively. A, Results of MSP in control and thyroid samples. Raji shows amplification only in the methylated reaction, but shows a lymphoblastoid cell line only in the unmethylated reaction. All of the TL cases (1, 7, and 12) and CLTH cases (21 and 26) show bands in the unmethylated reaction, because intermingling reactive cells are always admixed in thyroid lesions. Cases 7, 12, and 21 show bands in the methylated reaction. $B$, Results of MSP in peripheral blood leukocytes. No case shows a band in the methylated reaction.
Table 2. Incidence of Methylation of DAP-Kinase Promoter Region According to Histological Subtypes

\begin{tabular}{lrl}
\hline \multicolumn{1}{c}{ Histology } & $\mathrm{n}$ & \multicolumn{1}{c}{ Methylated } \\
\hline Thyroid lymphoma & 19 & $6 / 19(84.2 \%)^{*}$ \\
DL & 9 & $8 / 9$ \\
FCCL & 5 & $4 / 5$ \\
MZL & 5 & $4 / 5$ \\
Chronic lymphocytic thyroiditis & 9 & $2 / 9(22.2 \%)^{*}$ \\
Total & 28 & $18 / 28(64.3 \%)$ \\
\hline
\end{tabular}

${ }^{*} p<0.01$.

of methylation in all cases (Fig. 1), indicating that the methylation occurred somatically in the lymphocytes infiltrated in the thyroid lesions. Decrease or absence of expression of DAP-Kinase induced by hypermethylation of the promoter region results in disruption of the apoptosis pathway triggered by some stimuli, leading to a prolongation of survival of lymphocytes in the lesional tissues. As a result gene abnormalities accumulate in the lesional lymphocytes, which might contribute to progression of CLTH to TL. This supposition is supported by previous reports describing the resistance of neoplastic cell lines to IFN- $\gamma$-induced apoptosis through decrease or absence of expression of DAP-Kinase at mRNA and protein levels (Katzenellenbogen et al, 1999; Kissil et al, 1997). Alternatively the DAP-Kinase expression and IFN- $\gamma$-induced apoptosis could be restored in these cells by treatment with a demethylating agent (Kissil et al, 1997).

$A$ recent study suggested that disruption of the Fas-Fas ligand apoptotic pathway through somatic mutation of the Fas gene is involved in the development of NHL (Grønbæk et al, 1998). Indeed 9 of 10 current TL cases with methylated DAP-Kinase gene had Fas mutations in the coding region of the death domain, that is, loss-of-function mutation (unpublished data). The question is whether the downregulation of DAP-Kinase expression really contributes to lymphomagenesis in TL. For this point the following findings must be addressed. First, DAPKinase is involved in apoptosis induced not only by Fas but also by IFN- $\gamma$ or TNF- $\alpha$. It functions downstream of MORT1 (mediator of receptor-induced toxicity-1) and caspase 8 and upstream of other caspases (Cohen et al, 1999), indicating that DAPKinase plays a major role in the apoptotic pathway triggered by several different stimuli, including FasFas ligand interaction. Second, tumor B-cells from $\mathrm{NHL}$ exhibit resistance to apoptosis mediated by Fas-Fas ligand interaction, and this resistance could not be overcome by induction of Fas expression (Plumas et al, 1998). This indicates a possibility of altered expression and/or function of components downstream of Fas. These findings suggest that down-regulation of DAP-Kinase plays a central role in prolongation of survival of lymphoid cells in the lesional tissues.

The methylation pattern of DNA is established early in development by a combination of demethylation and de novo methylation of cytosine residues, pre- 
dominantly at $\mathrm{CpG}$ sites, and stably maintained through subsequent cell divisions by DNA (cytosine5-)-methyltransferase (DNA methyltransferase) (Baylin et al, 1998). Although the mechanisms underlying the alterations of DNA methylation remain unclear, a number of findings support the conclusion that increased activity of DNA methyltransferase may be associated with tumor development (Kautiainen and Jones, 1986).

\section{Materials and Methods}

\section{Case Selection}

Thyroid specimens were collected from 19 patients with TL and 9 with CLTH admitted to the Kuma Hospital (Kobe, Japan) or Osaka University Hospital (Suita, Japan) during the period 1992 to 1998. Criteria for diagnosis of CLTH included increased consistency of the thyroid gland, occasional hypothyroidism, high level of $\mathrm{TSH}$, low ${ }^{123}$ I-uptake, and presence of antimicrosomal and/or antithyroglobulin antibodies in the serum. Histologic findings of CLTH included lymphocytic infiltration, usually forming lymphoid follicles with germinal centers, varying degrees of fibrosis, and oxyphilic change or squamous metaplasia in the epithelial cells of the thyroid follicles. All patients with CLTH and all but 3 with TL were female. They received open biopsy or hemithyroidectomy at ages ranging from 27 to 89 (median 67) years in TL and 50 to 68 (median 61) years in CLTH (Table 1). All patients with TL had a 2-month to 22-year history of CLTH. Histologic specimens were fixed in $10 \%$ formalin and routinely processed for paraffin-embedding. Histologic sections, cut at $5 \mu \mathrm{m}$, were stained with hematoxylin and eosin, and were reviewed by one of the authors (KA). TLs were classified according to the Revised European American Lymphoma (REAL) classification (Harris et al, 1994). Rearrangement of immunoglobulin heavy chain gene was examined in 4 cases with CLTH and 16 cases with TL by Southern blot analysis with $\mathrm{J}_{\mathrm{H}}$ probe.

\section{DNA Extraction}

Fresh frozen tissues obtained by surgical resection or open biopsy were stored at $-80^{\circ} \mathrm{C}$ until use. Genomic DNA was extracted from frozen tissues and PBL by a standard phenol/chloroform procedure.

\section{Methylation-Specific PCR}

For methylation-specific PCR (MSP) we modified DNA with sodium bisulfite to convert all unmethylated cytosines to uracils, not converting methylated cytosines, and subsequent amplification with primers designed to distinguish the methylated from the unmethylated sequences in bisulfite-modified DNA. Bisulfite modification was performed as previously described (Herman et al, 1996) with some modification. Briefly $1 \mu \mathrm{g}$ of genomic DNA was denatured in $0.5 \mathrm{~m} \mathrm{NaOH}$ and modified by $10 \mathrm{~mm}$ hydroquinone (Sigma, St. Louis, Missouri) and $3 \mathrm{~m}$ sodium bisulfite (Sigma). Modified DNA was purified using the Wizard DNA Clean-up system (Promega, Madison, Wisconsin), treated with $0.3 \mathrm{~m} \mathrm{NaOH}$, precipitated with etha- nol, and resuspended in $20 \mu$ of water. MSP was carried out with primer pairs specific for the methylated or bisulfite-converted unmethylated promoter region of DAP-Kinase (Katzenellenbogen et al, 1999) under the following conditions: $95^{\circ} \mathrm{C}$ for 10 minutes followed by 40 cycles at $95^{\circ} \mathrm{C}$ for 1 minute, $60^{\circ} \mathrm{C}$ for 1 minute, $72^{\circ} \mathrm{C}$ for 1 minute, and a final extension at $72^{\circ} \mathrm{C}$ for 10 minutes. PCR products were run on the $3 \%$ NuSieve agarose gels, stained with ethidium bromide, and observed under ultraviolet illumination. DNA extracted from a Burkitt's lymphoma cell line (Raji) and a lymphoblastoid cell line were used as the methylated and the unmethylated controls, respectively.

\section{Statistical Analysis}

Fisher's exact test was performed to evaluate the differences in frequency of methylation in the TL and CLTH cases.

\section{References}

Aozasa K (1990). Hashimoto's thyroiditis as a risk factor of thyroid lymphoma. Acta Pathol Jpn 40:459-468.

Aozasa K, Ueda T, Katagiri S, Matsuzuka F, Kuma K, and Yonezawa T (1987). Immunologic and immunohistologic analysis of 27 cases with thyroid lymphomas. Cancer 60: 969-973.

Baylin SB, Herman JG, Graff JR, Vertino PM, and Issa JP (1998). Alterations in DNA methylation: A fundamental aspect of neoplasia. Adv Cancer Res 72:141-196.

Cohen O, Feinstein E, and Kimchi A (1997). DAP-Kinase is a $\mathrm{Ca}^{2+} /$ calmodulin-dependent, cytoskeletal-associated protein kinase, with cell death-inducing functions that depend on its catalytic activity. EMBO J. 16:998-1008.

Cohen O, Inbal B, Kissil JL, Raveh T, Berissi H, SpivakKroizaman T, Feinstein E, and Kimchi A (1999). DAP-Kinase participates in TNF- and Fas-induced apoptosis and its function requires the death domain. J Cell Biol 146:141-148.

Counts JL and Goodman JI (1995). Alterations in DNA methylation may play a variety of roles in carcinogenesis. Cell 83:13-15.

Deiss LP and Kimchi A (1991). A genetic tool used to identify thioredoxin as a mediator of a growth inhibitory signal. Science 252:117-120.

Deiss LP, Feinstein E, Berissi $H$, Cohen $O$, and Kimchi $A$ (1995). Identification of a novel serine/threonine kinase and a novel $15-\mathrm{kD}$ protein as potential mediators of the interferoninduced cell death. Genes Dev 9:15-30.

Grønbæk K, Straten PT, Ralfkiaer E, Ahrenkiel V, Andersen MK, Hansen NE, Zeuthen J, Hou-Jensen K, and Guldberg P (1998). Somatic Fas mutations in non-Hodgkin's lymphoma: Association with extranodal disease and autoimmunity. Blood 92:3018-3024.

Harris NL, Jaffe ES, Stein H, Banks PM, Chan JKC, Cleary ML, Delsol G, Wolf-Peeters CD, Falini B, Gatter KC, Grogan TM, Isaacson PG, Knowles DM, Mason DY, Muller-Hermelink HS, Pileri SA, Piris MA, Ralfkiaer E, and Warnke RA (1994). A revised European-American classification of lymphoid neoplasms: A proposal from the international lymphoma study group. Blood 84:1361-1392. 
Herman JG, Graff JR, Myöhänen S, Nelkin BD, and Baylin SB (1996). Methylation-specific PCR: A novel PCR assay for methylation status of $\mathrm{CpG}$ islands. Proc Natl Acad Sci USA 93:9821-9826.

Holm FM, Blomgren H, and Lowhagen H (1985). Cancer risks in patients with chronic lymphocytic thyroiditis. N Eng J Med 312:601-604.

Inbal B, Cohen O, Polak-Charcon S, Kopolovic J, Vadai E, Eisenbach L, and Kimchi A (1997). DAP kinase links the control of apoptosis to metastasis. Nature 390:180-184.

Katzenellenbogen RA, Baylin SB, and Herman JG (1999). Hypermethylation of the DAP-Kinase CpG island is a common alteration in B-cell malignancies. Blood 93:4347-4353.

Kautiainen TL and Jones PA (1986). DNA methyltransferase levels in tumorigenic and nontumorigenic cells in culture. J Biol Chem 261:1594-1598.
Kissil JL, Feinstein E, Cohen O, Jones PA, Tsai YC, Knowles MA, Eydmann ME, and Kimchi A (1997). DAP-Kinase loss of expression in various carcinoma and B-cell lymphoma cell lines: Possible implications for role as tumor suppressor gene. Oncogene 15:403-407.

Laird PW and Jaenisch R (1996). The role of DNA methylation in cancer genetics and epigenetics. Annu Rev Genet 30:441464.

Plumas J, Jacob MC, Chaperot L, Molens JP, Sotto JJ, and Bensa JC (1998). Tumor B cells from non-Hodgkin's lymphoma are resistant to CD95(Fas/Apo-1)-mediated apoptosis. Blood 91:2875-2885. 